\title{
Descartes: da unidade originária da razão e seus desdobramentos
}

\section{Descartes: the originary unity of reason and its unfoldings}

\author{
CÉSAR AUGUSTO BATTISTI ${ }^{1}$
}

Resumo: $\mathrm{O}$ texto propõe discutir a tese cartesiana da unidade originária da razão e os diferentes tipos de unidades dela decorrentes. A questão de fundo é que a divisão excessiva a que foram submetidas as ciências propõe um movimento de refluxo à sua própria lógica, por meio da busca de certas dimensões unificadoras. Ora, é esse retorno originário que pode muito bem contribuir para o debate atual referente à questão da interdisciplinaridade.

Palavras-chave: Descartes. Razão. Unidade. Ciência. Interdisciplinaridade.

Abstract: The paper aims to discuss the cartesian view of the original unity of reason and the different types of units of it. The bottom line is that the division that underwent sciences proposes a move reflux to its own logic, through the pursuit of certain unifying dimensions. Now, is this original return which may well contribute to the current debate regarding the issue of interdisciplinarity.

Keywords: Descartes. Reason. Unit. Science. Interdisciplinarity.

\section{Introdução}

O presente texto pretende discutir a tese cartesiana da (i) unidade originária da razão e os diferentes tipos de unidades dela decorrentes ou nela conectados, dentre os quais se destacam: (ii) a unidade sob a perspectiva da inteligibilidade das coisas, (iii) a unidade sob a perspectiva da aprendizagem, (iv) a unidade das operações mentais; (v) a unidade de procedimentos metodológicos, (vi) a unidade do ponto de vista categorial, (vii) a unidade de

1 Professor dos cursos de Graduação e Mestrado em Filosofia da UNIOESTE. ExTutor do PET-Filosofia da UNIOESTE (2006-2010). Endereço eletrônico: cesar. battisti@hotmail.com 
Descartes: da unidade originária da razão e seus desdobramentos

fundamento, (viii) a unidade do saber e das ciências em geral. Seria possível apontar outros tipos de unidades ou desdobramentos dessas unidades indicadas, tais como: (ix) a unidade por categoria substancial, (x) a unidade do ser humano, (xi) a unidade entre o racional e o real e (xii) a unidade do criador e de seu ato criativo.

Descartes afirma textualmente essa tese central da unidade em diferentes obras, embora nem sempre da mesma forma ou com o mesmo teor. Ela aparece também, em alguns momentos, apenas sub-repticiamente ou, então, simplesmente pressuposta. De todo modo, é uma tese de fundo do pensamento cartesiano.

Como ilustração, cabe destacar as Regras para a direção do espírito (escritas na década de 1620 , possivelmente em 1628) e a Carta-prefácio dos Princípios da filosofia (escrita na década de1640), obras que comprovam a presença da tese em períodos distintos da vida do filósofo e parecem denunciar sua permanência no horizonte do imaginário cartesiano, mesmo que de forma latente ou velada. A Carta-prefácio, por exemplo, nos apresenta a famosa árvore da sabedoria (AT IX-II, p. 14), ${ }^{2}$ metáfora utilizada para mostrar a organicidade e imbricação entre as diferentes disciplinas, todas elas compondo a Sabedoria humana. Ela também trata da imbricação entre os princípios primeiros e as outras verdades, evidenciando a "estrutura de um sistema de conhecimento" (AT IX-II, p. 2). As quatro partes dos Princípios da Filosofia (e a intenção do autor de escrever outras partes), cada qual tratando de disciplinas distintas, pretendem realizar essa unidade do saber. ${ }^{3}$ As Regras procedem de modo distinto, mas não deixam de se harmonizar com os Princípios. Elas serão examinadas mais detalhadamente abaixo.

\section{A unidade originária da razão}

A primeira reflexão cartesiana no sentido da defesa da unidade

2 Sigla utilizada para indicar as obras completas de Descartes, seguida de volume e paginação. Ver na bibliografia: Euvres de Descartes, publicadas por Charles Adam e Paul Tannery (AT).

3 Descartes pretende apresentar nos Princípios uma exposição de conjunto de sua filosofia, e fazer deles uma Suma de Filosofia e um curso completo de filosofia. Cf. Carta a Huygens de 31 de janeiro de 1642 (AT III, p. 523) e as Cartas a Mersenne de 22 de dezembro de 1641 (AT III, p. 465) e de 11 de novembro de 1640 (AT III, p. 233). 
do saber e das ciências aparece em uma de suas primeiras obras, as Regras para a direção do espírito. Embora algumas das ideias que compõem essa proposta de Descartes estejam presentes em outros textos, principalmente no Discurso do método, ${ }^{4}$ eu vou me ater fundamentalmente às Regras. Na Regra I - portanto, nas primeiras linhas do texto - Descartes apresenta uma comparação entre a razão e o Sol, e afirma que, da mesma forma que o Sol ilumina as coisas e as torna visíveis, assim também a razão humana ilumina, com sua luz natural, os objetos e os torna visíveis ao processo de conhecimento. Tal como sem sol ou sem luz as coisas não podem ser vistas, assim também as coisas a serem conhecidas precisam ser iluminadas pela luz da razão, sem a qual permanecem na plena escuridão e, portanto, inacessíveis ao conhecimento. Aqui aparece indiretamente a velha analogia entre a visão e a razão, entre o olho e a razão, que percebem graças a uma luz (natural e não divina) jogada sobre os objetos.

Assim, continua Descartes, a luz da razão é condição para o conhecimento das coisas, tal como o sol é condição para a visibilidade dos objetos em geral. Ambos são condição e, portanto, são previamente dados, são anteriores à relação que eles possibilitam. A relação sujeito - objeto do conhecimento é condicionada pela existência prévia da luz da razão que os constitui como tais.

Ademais, diz Descartes, essa luz da razão, como a do Sol, é única e sempre a mesma, por mais distintos e diferentes que sejam os objetos iluminados. Essa luz não sofre influência da diversidade dos objetos; ela não precisa se adaptar a eles nem se modificar em razão da diferença entre eles. Ao contrário, são eles que devem se deixar homogeneizar pela unidade da razão: eles devem ser receptivos à sua luz e, como tais, deixam de ser apenas coisas para se tornar objetos iluminados, todos eles, por ela. Aqui nasce a noção de inteligibilidade e de sua unidade, ainda que de forma indeterminada: o ato de compreender as coisas exige uma iluminação que homogeneíza todas elas, na medida em que elas refletem a luz e se tornam visíveis por meio dela. A noção de unidade sob a perspectiva da inteligibilidade (unidade tipo ii-1) consiste

\footnotetext{
4 A primeira frase do Discurso do método afirma a unidade da razão e a igualdade do poder de conhecer entre os homens: "O bom senso é a coisa do mundo melhor partilhada"; "o poder de bem julgar e distinguir o verdadeiro do falso, que é propriamente o que se denomina o bom senso ou razão, é naturalmente igual em todos os homens" (DESCARTES, 1993, p. 29).
} 
Descartes: da unidade originária da razão e seus desdobramentos

no fato de que todos os objetos, para serem captados pela razão, devem se submeter a um primeiro tipo de homogeneidade, aquela que os torna visíveis à razão: algo é visível para alguém que o vê, e esse alguém o vê a partir de determinada estrutura que possibilita a visão. ${ }^{5}$ Essa estrutura é uma só e única, dado que a razão é única.

Ora, a razão é única e una; e, portanto, a estrutura que permite a inteligibilidade das coisas é também uma só e única. E não há motivo algum para pressupormos a necessidade de mais de uma luz ou de diferentes luzes. Dessa tese cartesiana, seguem outras consequências importantes ao nosso tema.

A primeira delas é a seguinte: não se pode confundir a construção das ciências com outras atividades humanas, cujos princípios são distintos, tal como é o caso das atividades manuais em geral. As artes manuais exigem habilidades distintas, de natureza corporal, na medida em que elas se distinguem entre si. Cada uma delas exige habilidades ou hábitos próprios. Assim, o agricultor, com sua mão calejada pelo uso da enxada, sente mais dificuldade para dedilhar o violão do que alguém que tem uma mão mais leve e dedos menos rígidos. Portanto, a arte da agricultura de algum modo exige uma habilidade que se opõe à exigida ao violonista. Isso ocorre com todas as atividades manuais, diz Descartes, exatamente porque elas exigem habilidades corporais, enquanto as ciências exigem habilidades intelectuais. Imaginem um boxeador, com seus dedos rígidos e duros, querendo se tornar um exímio tocador de cavaquinho. As duas atividades são praticamente incompatíveis.

Tais atividades manuais são de natureza distinta daquela envolvida na busca do saber. Elas exigem habilidades corporais, antes de tudo. E o corpo não tem a unidade originária que a razão tem. Vemos já aqui os germes da distinção radical entre corpo ealma que Descartes fará mais tarde na metafísica. Como o corpo é uma entidade material divisível - divisível infinitamente, para Descartes - ele não tem uma unidade originária e inalienável, tal como a razão, que é indivisível e sempre a mesma em qualquer atuação; e, assim, as habilidades corporais são de natureza absolutamente distinta das atividades intelectuais, mas também distintas entre si, enquanto as intelectuais são oriundas de um fundo comum.

5 Isso não significa que o real deva se subordinar ao racional. Como diz a Meditação Quinta, "meu pensamento não impõe necessidade alguma às coisas" (DESCARTES, 1993, p. 125). 
Aqui temos uma clara oposição entre Descartes e Aristóteles. Aristóteles não só admitia a distinção originária das ciências a partir de seus objetos, como dizia que o intelecto precisa se adaptar a essa diversidade e adquirir, para cada uma delas, hábitos distintos. Descartes não admite está primazia dos objetos, e discorda de Aristóteles quanto à similaridade entre atividades intelectuais e atividades artístico-manuais.

Uma segunda consequência da tese da unidade da razão, em Descartes, é a de que, enquanto as habilidades corporais de algum modo se opõem entre si, as habilidades intelectuais, por brotarem da mesma e única razão, são sempre as mesmas e se reforçam, se fortificam mutuamente. Assim, a aquisição de uma ciência tornanos mais hábeis à aquisição das outras ciências. Vejam que coisa curiosa: Descartes está dizendo que a aprendizagem de uma ciência auxilia na aprendizagem de outra, porque ambas exercitam a mes-ma e única razão. Poderíamos extrair daí consequências pedagógicas interessantes. Aqui aparece claramente a unidade na perspectiva da aprendizagem (unidade tipo iii): sendo una e idêntica a força racional, ela se fortalece em cada novo exercício, por mais diferente que seja o campo de atuação, diferentemente de habilidades corporais que se excluem ou se prejudicam reciprocamente. Aqui a unidade originária da razão se desdobra na sua maneira única de proceder e de aprender a cada novo exercício. Assim, mais importante do que apreendermos um novo objeto é o treinamento para a apreensão de um novo objeto. Em regras posteriores, principalmente nas Regras IX e X, Descartes dá exemplos de como devemos praticar atividades simples, como o tear ou o trabalho dos artesãos, a fim de cultivarmos a perspicácia e a sagacidade e, com isso, treinarmos nosso intelecto à apreensão das coisas com acuidade e clareza e ao ordenamento delas entre si. ${ }^{6}$

A terceira consequência é que a unidade originária da razão implica uma unidade em seus procedimentos, uma unidade metodológica (unidade tipo v), por mais distintos que sejam os objetos, bem como uma unidade de suas operações intelectuais (unidade do tipo iv). Não haverá, como veremos mais adiante, incompatibilidade entre unidade do ponto de vista do sujeito e

6 Não se trata aqui de desfazer a diferença entre o modo de atuação da mente e o das atividades corporais, mas apenas de aprender com procedimentos simples, nos quais a razão atua natural e espontaneamente. 
diversidade do ponto de vista do objeto. Da unidade da razão brota, portanto, a tese cartesiana da unidade de sua atuação, entendida em seu sentido amplo, sendo a metodológica e a pedagógica duas dentre suas espécies. Mas, por outro lado, nascem as dificuldades de como conciliar essa unidade originária da razão, lançada como tese inicial, e a produção dos conhecimentos sobre as diferentes coisas. Afinal, Descartes não nega a diversidade dos objetos, a distinção entre eles.

Para resolver esse problema, Descartes terá que distinguir quatro ou cinco elementos que compõem a sua epistemologia, às quais se remetem a diferentes tipos de unidade: a sua concepção de conhecimento (unidade do tipo viii); a teoria das faculdades mentais (unidade do tipo iv); a teoria dos objetos e seu sistema categorial (unidade do tipo vi); e a teoria do método (unidade do tipo v).

\section{$2 \mathrm{O}$ que é conhecimento?}

Para Descartes, conhecer é estabelecer relações fundamentais, de natureza cognitiva, entre coisas dentro de um certo domínio. Conhecer pressupõe relacionar, e relacionar pressupõe ordenar dentro do princípio de que o mais simples é anterior ao composto, e o complexo é composto por elementos simples. É por isso que a reflexão cartesiana sobre a matemática assume uma função paradigmática: ela mostra como se constitui uma ciência como "conhecimento certo e evidente", como a mente deve se restringir, para conhecer, ao que pode ser "certo e indubitável", graças ao fato de que toda ciência deve lidar antes de tudo com "objetos puros e simples" e com relações ou deduções estabelecidas entre eles de modo racional, isto é, de forma transparente à razão. Assim, por um lado, a razão, cuja unidade deve ser resguardada, mantém seu domínio sobre as coisas, uma vez que os objetos puros e simples lhe são transparentes e cujas cadeias dedutivas ela mesma as constrói. É assim que procede a matemática. Mas não devemos seguir a matemática simplesmente, a não ser porque ela expressa o modo em si mesmo de a razão agir: a matemática é expressão do modo de proceder da razão una e idêntica a si mesma. Não é a razão que imita a matemática, mas é a matemática que expressa o modo de a 
razão atuar.

Nesse sentido, conhecer racionalmente é construir uma ciência transparente ao ser racional, bem como ordená-la a partir dos elementos mais simples até os mais complexos. Dessa forma, uma disciplina forma um sistema de conhecimentos, só então chamado de ciência, porque os conhecimentos são ordenados pelo critério da simplicidade e da dependência.

A ciência, portanto, é constituída por conhecimentos certos e indubitáveis, articulados entre si de modo a formar um sistema, graças à possibilidade de a razão estabelecer relações entre os objetos e, portanto, os objetos se deixarem medir e ordenar por tais relações. Aqui aparece a unidade do saber em geral; e das ciências, até onde seus objetos se articulam ao redor de uma medida e de um ordenamento entre eles (unidade tipo viii). Se partíssemos da diversidade dos objetos, do fato de serem separados e desconectados, essa concepção de conhecimento não poderia ser assumida por Descartes, uma vez que o conhecimento entendido como construção de relações pressupõe a submissão das coisas a serem conhecidas às regras dessa construção de natureza relacional.

\section{As operações do espírito}

A esta perspectiva do conhecimento ou dos objetos do conhecimento, que existem como objetos definidos como relações entre coisas - e não como coisas tal como o homem comum entende -, a tese da unidade da razão, para se sustentar, deve mostrar sua unidade por meio de suas operações (unidade tipo iv). Tal como o Sol ilumina indistintamente as coisas do mundo por meio de sua luz, a razão o faz por meio de suas operações. Mas há uma diferença entre o Sol e a razão: podemos constatar diretamente que há um Sol que nos ilumina, enquanto no caso da razão não temos acesso direto a ela senão pelas suas manifestações e pelas suas operações.

Dada a caracterização dos objetos do conhecimento como objetos simples e aqueles formados por suas composições, as operações mentais devem satisfazer a esses requisitos e corresponder, enquanto faculdades cognitivas, ao que são os objetos, para poder captá-los: aqui já se manifesta outro tipo de unidade, entre o racional e o real (unidade do tipo xi), na medida em que nossa 
Descartes: da unidade originária da razão e seus desdobramentos

mente é capaz de captar o desconhecido, que se encontra para além dela. Por isso, Descartes estabelece que o intelecto possui duas operações que lhe são inerentes e suficientes ao propósito aqui apresentado. São duas operações inatas, a intuição e a dedução, pelas quais se produz o conhecimento. Elas são responsáveis pelo processo de apreensão e de concatenação, isto é, pelas construções de relações cognitivas entre os objetos no interior de um campo científico.

A intuição permite a apreensão de conhecimentos mais simples e fundamentais, tal como ocorre nas operações matemáticas mais simples. Intuir éaprender o mais diretamente possível. Por sua vez, a dedução permite a construção de cadeias de conhecimentos, permite a derivação de um conhecimento a partir de outro, de modo que seja possível extrairmos conclusões cada vez mais distantes.

Contudo, não se pode confundir, aqui, a dedução cartesiana com a de natureza lógica (criticada por Descartes), apoiada sobre uma regra lógica: a dedução cartesiana é a apreensão de ligações por intuição. Caso contrário, ela também estaria alienando sua autonomia e se submetendo a regras que, embora racionais, seriam independentes da própria razão. Por isso, a dedução não tem uma natureza distinta da intuição, mas somente se distingue por exigir que o intelecto preste atenção a um número maior de elementos, não podendo abarcá-los a todos de um relance. Ela, contudo, se reduz mais cedo ou mais tarde à intuição: a apreensão de sua conclusão é por intuição.

Além disso, não podemos adquirir tais capacidades. Elas são inatas; são a própria razão em funcionamento. No máximo, podemos treiná-las, mas, rigorosamente, não podemos aprender a realizá-las, tal como não podemos aprender a ser racionais: ou nós já somos racionais ou jamais seremos.

Descartes não pode admitir a inexistência de operações inatas. Caso contrário, a razão não poderia agir, ou agiria somente por reflexo ou passivamente. E isso comprometeria a autonomia da razão e do conhecimento. Tampouco podemos aprender a realizá-las, ainda que podemos aperfeiçoar seu funcionamento: elas ocorrem com autonomia e certo caráter automático diante de um conteúdo que preenche as condições para ser apreendido. Elas correspondem à construção do conhecimento como construção de 
relações entre coisas.

Em síntese, a razão atua por meio de duas operações inatas, a intuição e a dedução (Regra III), operações que garantem autonomia, segurança e unidade à razão, bem como transparência aos objetos apreendidos.

Essa é a ideia da unidade das operações mentais (unidade do tipo iv).

\section{A homogeneização dos objetos}

Voltemos, agora, novamente a considerar o status dos objetos do conhecimento. Afirmamos acima que eles, tal como ilustra a matemática, devem ser simples e transparentes à razão, e suas relações ou deduções estabelecidas rigorosa e racionalmente, de modo que suas ligações sejam também transparentes à razão e construídas por ela. Agora, o que significa a afirmação de que os objetos devam ser tais que se deixam captar pelo intelecto? $\mathrm{O}$ que há nos objetos matemáticos para que sejam considerados transparentes, sejam eles simples sejam eles complexos, e sua complexidade se deixe examinar completamente pela razão? Não basta dizer que os objetos devam ser simples ou compostos pelos simples, se não apontarmos os critérios ou modos pelos quais eles preenchem esses requisitos. A questão é, por exemplo: como um objeto físico poderia se tornar acessível ou inteligível à razão tal como um objeto matemático?

A solução de Descartes é a seguinte: todo objeto, para preencher esse critério e se deixar lidar pelo intelecto, deve se submeter a dois requisitos: ele deve se deixar medir e deve se deixar ordenar pela razão. Isto é: conhecer racionalmente significa medir e ordenar objetos. Essa é a proposta cartesiana de uma mathesis universalis (Regra IV) de onde resulta a tese da homogeneidade dos objetos agora com a estipulação dos critérios mais gerais que permitem a sua compreensão ou sua inteligibilidade (unidade tipo ii-2). Tais critérios de inteligibilidade dos objetos se constituem no primeiro nível categorial estipulado por Descartes: é a tese do cumprimento dos parâmetros mais gerais indicados pela razão, a ordem e a medida (unidade tipo vi-1). A mathesis universalis estipula o nível categorial mais geral para a inteligibilidade de uma 
Descartes: da unidade originária da razão e seus desdobramentos

coisa, qualquer que seja. Ela é, portanto, distinta do método: ela determina como se dá o conhecimento como estabelecimento de relações entre as coisas, mas não propõe regras de atuação da razão na produção do conhecimento.

Em outros termos, Descartes reconhece que os objetos, por mais diferentes que sejam, devem preencher determinados requisitos necessários para que a mente possa pensá-los, iluminálos, examiná-los, enfim, manipulá-los e conhecê-los. Isso significa primeiramente que a mente deve poder medi-los. E, para tal, é preciso que os objetos tenham uma grandeza e, sob esta, uma unidade comum. A medida pressupõe uma unidade de medida, e somente grandezas possibilitam se deixam medir. Conhecer é, portanto, medir; e, medir os objetos entre si, é possibilitar que a razão os meça por ela mesma.

Não devemos restringir, entretanto, a medida a objetos matemáticos. Ela tem um sentido mais amplo. Há medida onde os objetos são homogêneos, pertencem à mesma natureza. Objetos de uma mesma ciência devem ter uma natureza comum, uma unidade comum.

Em segundo lugar, se os objetos são homogêneos ou têm uma natureza comum, o que os distingue é seu grau de complexidade ou de composição em relação aos mais simples. O segundo critério da mathesis é a ordem, visto que as coisas se ordenam dentro do critério da simplicidade e da dependência. Eles formam relações entre si, cujo ordenamento se dá pela relação de composição e dependência entre eles.

Assim, os objetos de uma ciência se dividem em simples e complexos, mas todos tendo uma natureza comum. Como tais, se distinguem entre si pelas relações mais simples e complexas que cada uma mantém, de modo que a sua natureza é exatamente da forma exigida pelas duas capacidades do intelecto para poder conhecê-los.

Essa tese da homogeneidade dos objetos por meio da mathesis universalis e seus dois critérios, a ordem e a medida, ao mesmo tempo em que dá determinação à noção de inteligibilidade e de manipulação das coisas tratadas anteriormente, nos fornece o primeiro sistema categorial cartesiano (unidade do tipo vi-1): as 
coisas, para poderem entrar no domínio do inteligível ou racional, devem se deixar dominar pelas categorias da medida e da ordem. Mais adiante, especificamente nas Regras VIII e XII, Descartes apresentará um sistema categorial complementar, baseado nas naturezas simples e suas misturas e composições.

\section{0 método}

Passemos ao próximo elemento componente da tese da unidade do saber e das ciências, o método. Esse é o elemento mais dinâmico dentre todos eles, pois é ele que produz o saber e é "dentro dele” que os outros aparecem. É por isso que o método é tão central para o filósofo.

Descartes afirma duas teses fundamentais. A primeira diz respeito à unidade ou universalidade do método. A segunda diz respeito às suas características gerais e suas funções.

Quanto à unidade do método, ela decorre diretamente das considerações feitas acima. Dada a unidade da razão e a homogeneidade dos objetos do conhecimento, o método não pode ser distinto para cada ciência, pois as ciências, sob os requisitos formais, têm objetos que preenchem as mesmas exigências e, sob esse ponto de vista, são idênticos. Não podemos partir da heterogeneidade aparente das coisas e concluir pela necessidade de distintos métodos. A razão opera por intuição e dedução, e os objetos, para serem conhecidos, precisam se deixar medir e ordenar por ela. O método é um conjunto de procedimentos que dá conta disso, e sua atuação torna a razão cada vez mais hábil nos diferentes domínios. Ele permite que as operações intelectuais ocorram nos mais distintos domínios de conhecimento. O método, portanto, é único, porque o modo de operar da razão dever ser único e porque os objetos do conhecimento foram submetidos a uma homogeneidade tal que não exigem um tratamento diferenciado para cada um deles.

Quanto às características gerais do método, para além de sua unidade e universalidade, são importantes aqui as seguintes. Primeiramente, é preciso separar e distinguir método e operações mentais. Método não é a mesma coisa que as operações mentais, a intuição e a dedução. Estas são inatas e não há como modificar sua 
Descartes: da unidade originária da razão e seus desdobramentos

natureza ou adquiri-las. O método é sua operacionalização, sim, mas não se confunde com elas: ele possibilita que elas ocorram, levando em conta também a forma como aparecem às coisas a serem conhecidas.

O método se distingue também da mathesis universalis. Esta apenas estipula os requisitos gerais dos objetos do conhecimento, a ordem e a medida. Ao contrário, o método precisa operar com tais requisitos efetivamente em um determinado domínio de objetos. A mathesis não fornece, por exemplo, qual é a medida de homogeneização de um domínio de objetos; é preciso estipular essa medida, encontrá-la de algum modo; a mathesis tampouco nos fornece a ordem de determinado conhecimento: o método precisa construí-la.

Há, porém, outra coisa que o método deve fazer: ele, em geral, não encontra os objetos já homogeneizados efetivamente; ele os encontra tal como eles se dão naturalmente, isto é, na sua diversidade e em meio ao nosso modo confuso de vê-los, em razão da natureza de nossa própria composição. Lembrem o que diz o Discurso do método: nós perdemos, desde a mais tenra idade, a possibilidade do "uso inteiro de nossa razão" e de tê-la como único guia. ${ }^{7}$ Assim, o método leva em conta a constituição complexa dos objetos, o modo complexo de eles se apresentarem a nós, modo complexo também em razão da composição do próprio homem, formado de corpo e alma.

É por isso que as primeiras regras do método insistem no cuidado que precisamos ter para o que aparenta ser claro e distinto e para evitar a precipitação, bem como na necessidade de partir do que é dado de forma complexa, diversificada, confusa, etc., e encontrar seus elementos fundamentais, simples, que ainda estão escondidos, mas devem estar presentes, para o conhecimento ser possível. E aqui percebemos a diferença entre as operações e o método: as operações afirmam que o simples é anterior ao complexo, pois o complexo é composto pelo simples e suas ligações. Assim, o simples é epistemicamente anterior e condição do complexo. Por outro lado, o método não começa pelo simples, mas deve buscá-

7 Diz o Discurso: "é quase impossível que nossos juízos sejam tão puros ou tão sólidos como seriam, se tivéssemos o uso inteiro de nossa razão desde o nascimento e se não tivéssemos sido guiados senão por ela" (DESCARTES, 1983, p. 35). 
lo, encontrá-lo; ele parte do complexo para encontrar o simples, pois o que lhe é dado são os problemas ou as coisas imersas em seus emaranhados e complexidades. Assim, o que as operações preconizam não pode ser um ponto de partida ou uma indicação imediata e direta do método. Na ordem epistemológica, o simples é anterior ao complexo; na ordem metodológica, o complexo é anterior (embora, em alguns casos, o simples possa se oferecer imediatamente), dado que o método deve considerar as coisas e como elas chegam até a razão (muitas vezes por meio do corpo). ${ }^{8}$

Com isso, resolvemos o problema existente entre a tese da unidade da razão frente à diversidade dos objetos. O método tem aqui uma função fundamental: ele parte desta diversidade aparente e a reconduz a seus elementos essenciais, que se deixam ordenar e medir. Com isso, a razão pode descobrir os seus elementos mais simples e o que deles é composto. Portanto, o método consegue articular o aparente desacordo entre a unidade dos modos de operar da razão com a diversidade das coisas. Por isso, não se pode confundir método com operações mentais: estas dizem respeito à natureza da razão, enquanto o método leva em conta a "exterioridade" e a complexidade dos "objetos do conhecimento".

O método confirma, sob o aspecto operacional, a unidade das ciências. Unidade das ciências significa, portanto, unidade da razão e de suas operações, mas também homogeneização dos objetos do conhecimento e recondução de algo alheio às suas condições e exigências da razão. O método, pressupondo a mathesis universalis, procede efetivamente à compreensão das coisas que se apresentam à mente. Na verdade, não é apenas o mundo que se apresenta dessa forma complexa e desconhecida: há a multiplicidade e complexidade das coisas e há também o modo complexo (e confuso) de percebêlas, pelo fato de sermos seres finitos e compostos de corpo e alma. Assim, a mente precisa lidar tanto com a complexidade do mundo quanto com seu modo complexo de existir, pela união entre ela e o corpo humano.

8 O caso do "cogito" é exemplar: ele é uma conquista, um resultado do processo da dúvida e não um ponto de partida. Como ponto de partida, ele, tomado na sua indubitabilidade e evidência plena, é estéril, seja porque é indubitável apenas em sua atualidade, seja porque uma evidência plena não pode revelar nada mais em razão exatamente de tudo já estar evidente. O “cogito”, diz Descartes, é como o ponto fixo de Arquimedes, que possibilita mover o mundo. Esse ponto, entretanto, nada faz sem a alavanca, sem o mundo e sem alguém que a utilize adequadamente. 
Descartes: da unidade originária da razão e seus desdobramentos

\section{Das coisas simples e sua classificação}

Em diferentes momentos das Regras, Descartes trata das chamadas natureza simples e de sua classificação, em contraposição às coisas complexas ou compostas. A Regra VIII afirma que, entre as naturezas simples, há apenas naturezas espirituais, corporais e comuns. São intelectuais ou espirituais, continua a Regra XII, as que são conhecidas apenas pelo e no entendimento, tais como o que é o conhecimento, a dúvida, a ignorância, a vontade e outras desse gênero; são materiais as que existem apenas nos corpos, como a figura, a extensão e o movimento; são comuns as atribuídas indistintamente aos corpos e aos espíritos, como a existência, a duração, a unidade e coisas semelhantes. ${ }^{9}$ Há ainda, entre essas coisas simples, as noções comuns ou axiomas e a negação ou privação das naturezas simples.

Esse conjunto de elementos, divididos em três grupos, fornecem um sistema categorial complementar (unidade do tipo vi-2) ao já apresentado acima, ao mesmo tempo em que antecipa, embora não trate aqui do infinito, dos tipos de substâncias, conforme afirmará em sua metafísica (unidade do tipo ix). Além disso, o reconhecimento de diferentes espécies de coisas é um atestado de que a razão unificante e homogeneizante reconhece minimamente a pluralidade de tipos de realidades. Os diversos tipos de homogeneidade (indeterminada, promovida pela mathesis e categorial) não significam, assim, uma tentativa de aniquilar a multiplicidade das coisas ou um simples reducionismo das diferentes coisas, embora haja no pensamento cartesiano um direcionamento à redução ou à recondução à unidade: parece não haver dúvida de que Descartes, em razão de suas teses de natureza epistêmica, tende a reconduzir as múltiplas coisas a determinadas categorias dentro das quais elas pertencem. A homogeneidade mesmo indeterminada (visto que não fornece nenhum parâmetro ainda) exige apenas a submissão das coisas à luz única e idêntica da razão como critério de inteligibilidade dessas coisas; a homogeneidade promovida pela ordem e medida exige que toda realidade cognoscível se submeta a esses critérios ou sistema categorial geral, o que não deixa de ser uma definição

9 A indicação dessas naturezas comuns à mente e ao corpo sofre variações nos diferentes escritos de Descartes, mas o princípio que a determina permanece o mesmo. 
do que seja conhecer: conhecer é construir relações entre coisas, e construir tais relações é ordená-las e medi-las; o sistema categorial classificatório é o reconhecimento de que o real não é todo ele homogêneo e, portanto, terá diferentes ordens e medidas: o fato de haver diferentes naturezas simples, reunidas em categorias distintas (materiais e espirituais), evidencia a existência de "reinos" substanciais distintos. A classificação das naturezas simples em diferentes espécies e a afirmação de que toda realidade é composta por elas e suas composições representa a tensão entre a tese da redução do real e o reconhecimento de uma multiplicidade mínima de coisas.

Essa é uma antecipação do que Descartes dirá mais tarde na metafísica: haverá, fundamentalmente, três tipos de realidade, a realidade infinita, as realidades espirituais e a realidade material ou extensa. E, assim, haverá três tipos de substâncias, a substância infinita, a espiritual e a material (unidade do tipo ix), embora o real não se reduza, rigorosamente, a essas três espécies de realidade. Há algumas outras coisas que não se encaixam nessas três categorias dadas acima. São exemplo disso: os objetos matemáticos, que são coisas (res), mas são pertencem a nenhum dos tipos de substâncias apontados acima; os axiomas e noções comuns, que não correspondem a coisas, embora sejam verdades; a natureza humana, embora seja emergente da união entre corpo e alma, lhes é irredutível e, portanto, não é apenas junção de ambas, mas algo novo e indecomponível, ainda que oriundo delas. ${ }^{10}$

Seja como for - e apesar das dificuldades enfrentadas pelo pensamento cartesiano -, é clara a unificação ou recondução das múltiplas coisas a certos gêneros, categorias, tipos de substâncias, direcionamento tomado a partir do princípio básico da unidade da razão e de sua noção de inteligibilidade. Não se pretende defender, aqui, a necessidade de o real se adequar ao racional, mas apenas as exigências racionais que se deva cumprir e a "harmonia" existente entre elas e o real.

Há, portanto, um sistema categorial básico (unidade do tipo vi-2) que comanda outros tipos de unidades. Se se preferir, a tese da unidade central "cede", em certa medida, e aceita a divisão do

$10 \mathrm{O}$ ser humano é corpo e alma, mas não se reduz à sua mera soma: ele é uma realidade emergente da união que não se reduz aos elementos componentes. Como "novo ser", apresenta uma nova unidade (unidade do tipo x). 
real em unidades secundárias: a unidade central se divide em unidades ao redor de três tipos de substâncias (unidade do tipo ix $)^{11}$; ela pressupõe uma "harmonia" entre conhecer e ser, entre racional e real (unidade do tipo xii), mas não impede que o real, em alguns momentos, se imponha ao racional, como é o caso da incompreensibilidade divina $^{12}$ e da incompreensibilidade intelectual dos fenômenos emergentes da união entre corpo e alma (unidade do tipo $\mathrm{x}$ ).

\section{Unidade de fundamento}

Vamos dar agora um passo adiante e examinar o pensamento de Descartes em sua época madura, caracterizada pela introdução de problemas metafísicos e pela preocupação com o fundamento do conhecimento. Examinaremos esse ponto principalmente a partir das Meditações.

Até então a posição de Descartes era epistemológica, sem se preocupar ainda com a busca de um fundamento metafísico do conhecimento. Teremos a oportunidade de perceber que Descartes continua a defender a tese da unidade das ciências, agora de uma forma diferente, mas sem abrir mão das teses anteriormente apresentadas. Não haverá oposição entre os dois pontos de vista, mas complementação e aprofundamento. Nesse sentido, ele reforça ou mesmo justifica aquelas teses anteriormente apresentadas.

Em síntese, a tese da unidade da razão recebe uma justificação metafísica por meio da instauração dos fundamentos do conhecimento e pelo conjunto todo da sua metafísica. A regra da verdade (tudo o que é claro e distinto é verdadeiro), a título de exemplo, retoma a teoria das operações mentais, a de que só podemos adquirir conhecimento por meio da intuição e da dedução. Lembremos que estas operações foram definidas como as formas de aquisição do conhecimento certo e evidente. $\mathrm{O}$ método encontra na metafísica uma ocasião para mostrar sua fecundidade

$11 \mathrm{O}$ pensamento espinosano é exemplo da retomada da tese da unidade central contra a da divisão em diferentes tipos de substâncias.

12 A incompreensibilidade divina nos remete a outro tipo de unidade, a do criador e de seu ato criativo (unidade do tipo xii). Deus é unidade e simplicidade absolutas, de onde se deduz a indistinção entre seus atos de querer (vontade) e seus atos de conhecer (entendimento) e, de um modo geral, de todas as suas ações. 
e continua a ser aquele que, ilustrado pela prática dos matemáticos, é agora "aplicado" à filosofia. O mesmo pode ser dito a respeito da tese da homogeneidade dos objetos, ainda que essa tese se torne mais complexa, na medida em que, levada aos extremos, ela cede à distinção entre os diferentes tipos de substâncias.

Conhecemos a estratégia montada por Descartes, principalmente na Primeira Meditação, para universalizar a dúvida a todo conhecimento possível, bem como a "intuição" da existência do ser pensante, paradigmaticamente apresentada com a famosa frase "penso, logo existo", e a prova da existência do Deus veraz e não enganador, de onde decorre o estabelecimento do critério da clareza e distinção como critério da verdade. Esse conjunto de estrutura metafísica se constitui o fundamento do conhecimento, tomado em sentidoamplo, cuja unidade se manifesta pela existência absoluta de uma base única e válida universalmente, composta pelos diferentes papeis exercidos por cada uma das partes dessa estrutura, solidárias entre si e instauradoras de uma unidade de fundamento (unidade do tipo vii).

É verdade que podemos reduzir essa noção de fundamento a Deus e ao cogito, ou a um ou outro, conforme as interpretações possíveis. Parece, contudo, mais interessante conceber essa noção de fundamento dentro dessa estrutura metafísica fundante ou como rede de objetos metafísicos e de suas articulações a partir da qual o real se deixa conhecer, dentro das quais o eu e Deus têm papéis capitais. Novamente voltamos à imagem da árvore da sabedoria, cujas raízes são a estrutura fundante da metafísica, o tronco é a física e os galhos as diferentes ciências, em especial, a mecânica, a medicina e a moral. Por meio dessa analogia, percebemos a fundamentação metafísica do conhecimento. A estrutura do saber se fundamenta em bases metafísicas.

A metafísica cartesiana, portanto, estabelece uma unidade de fundamento. Ela, ao mesmo tempo, reconhece a irredutibilidade do real a apenas um tipo de categoria. O ser pensante, na Segunda Meditação, se mantido isoladamente, não tem autossubsistência. Ele se abre ao infinito e necessita do infinito, que, por sua vez, se deixa conhecer, embora não se deixe compreender totalmente. O ser pensante também se encontra conectado com o mundo, e o homem só surge da união de uma entidade espiritual e uma de natureza 
material. Por detrás dessa tese da unidade originária e fundante e da tese da aceitação de certa divisão dessa unidade encontra-se a tese da indissociabilidade entre entendimento e vontade divinas e da unidade de seu ato de criação das coisas e do mundo finito: as diferentes unidades parecem se remeter a unidade absoluta do criador (unidade do tipo xii), que instaurou as demais, como a da razão e a da "harmonia" entre o real e o racional, pressupostas pelo método.

E, assim, vê-se como a tese da unidade é subjacente a todo pensamento cartesiano. $\mathrm{O}$ racionalismo cartesiano tende a ser reducionista, mas não deixa de admitir a impossibilidade de um reducionismo absoluto. Ele se move entre a multiplicidade (de substâncias) aristotélica (excessivamente complacente com um realismo acrítico) e o radicalismo racionalista espinosano, defensor da recondução de todas as coisas a uma única substância, sem cair nessas duas posições extremas.

\section{A atualidade da questão}

Descartes está entre os pensadores que mais defenderam a tese da unidade das ciências; talvez seja seu maior defensor. Contudo, ele é um pensador do século XVII, do início da modernidade, cujas questões não são mais as nossas e, assim, talvez pudéssemos nos perguntar se tem sentido discutirmos esse tema em pleno século XXI. Poderíamos nos perguntar, portanto, se, embora devamos reconhecer a agudez da reflexão cartesiana e a pertinência circunstancial de seu ponto-de-vista, teses como esta não têm apenas um valor simbólico ou historiográfico? A tese da unidade da ciência é falsa, dirá qualquer cientista atual em sua sã consciência; com efeito, quem duvida da diferença entre as ciências, a começar pela diferença de seus objetos, mas também pelos distintos métodos e procedimentos que utilizam. O que há de comum, por exemplo, entre matemática e biologia?

Portanto, haverá algum sentido para que, atualmente, voltemos ao tema? É possível ainda falar em unidade das ciências? Há alguma real importância em retomarmos as discussões feitas por filósofos como Descartes? 
A resposta imediata parece ser negativa: não há sentido em voltarmos a esse velho tema. Os agentes produtores do conhecimento (os cientistas, os nossos sábios), na contemporaneidade, incorporaram a lógica da sociedade do trabalho e a aperfeiçoaram ainda mais: há uma espécie de divisão do trabalho intelectual, a exemplo da divisão do trabalho em geral, instituída no interior da sociedade produtora do conhecimento, cujo resultado é a distinção cada vez mais crescente de funções e de resultados, e uma especialização cada vez maior dos seus sujeitos-agentes. É uma característica central da ciência atual, não só a obediência rigorosa ao princípio metodológico da boa delimitação de um objeto de pesquisa, mas a crescente necessidade da especialização e, com isso, a separação cada vez maior entre diferentes áreas do saber.

Logo, não só parece não ter sentido a discussão da unidade das ciências, como também a lógica aponta para uma separação cada vez mais crescente e radical entre elas, de sorte que poderá ocorrer que elas venham a se tornar absolutamente estranhas e incomunicáveis entre si.

Por outro lado, poderíamos questionar essa divisão entre os campos do saber, entre as ciências. Com efeito, nem sempre é fácil separá-las ou separar os objetos de estudo de cada uma. Houve um tempo em que as ciências naturais se chamavam filosofia natural e formavam um saber unificado, apesar de suas divisões internas. Ora, poderia alguém dizer: a natureza é em si mesma una e, portanto, as divisões que, nela, a ciência introduz são superficiais ou pelo menos têm como critério algo diferente da diversidade dos objetos, que neste caso parece não haver. Poder-se-ia, portanto, questionar o critério da diversidade dos objetos de onde decorreria a diversidade das ciências, pois o dado imediato é que os objetos não são tão distintos quanto nos parecem. Podemos falar da natureza física como um todo. Podemos falar da natureza humana como um todo.

Senão como explicar o surgimento de novas ciências, que incorporam partes do terreno de outras já existentes? Se a química tem um objeto distinto do da biologia, como pôde surgir a bioquímica? A bioquímica junta duas coisas distintas e incompatíveis? E, se eram incompatíveis, como se tornaram compatíveis? Surgiu um novo objeto, com características novas? O 
Descartes: da unidade originária da razão e seus desdobramentos

que, portanto, é um objeto de conhecimento?

Estas são algumas das questões ainda atuais que não podem ser respondidas por uma perspectiva que não pensa em alguma medida a tese da unidade das ciências. Esse é um primeiro indício de que a reflexão sobre a unidade da ciência é ainda atual.

Mas podemos citar outros indícios. Um deles liga-se ao próprio nome "ciência”. Nenhum campo do conhecimento abre mão desse nome; talvez a filosofia seja a exceção, desde que se entenda por ciência algo mais restrito do que conhecimento em geral ou como sinônimo de conhecimento positivo. Deve haver, portanto, algo de comum ao que os produtores do conhecimento fazem: todos fazem ciência ou produzem conhecimento, e fazem questão de chamá-lo como tal. Será que esse nome é meramente uma lembrança da unidade perdida, tão almejada por Descartes? Representa uma mera atitude saudosista que carregamos apenas inconscientemente? Ou será que é apenas uma marca de um produto de venda fácil? Embora para muitos seja apenas isso, deve haver algo que une todas as atividades ou produtos que recebem o qualificativo "científico".

Um terceiro indício da atualidade do tema diz respeito a certas carências e deficiências sentidas pelos cientistas e pelos que ensinam ciências. Podemos citar alguns exemplos.

Qual o significado das discussões atuais sobre o tema da interdisciplinaridade do conhecimento? O que significa uma pesquisa transdisciplinar? Qual a razão da necessidade de haver pesquisas interdisciplinares? Isso parece indicar que às diferentes ciências falta algo que deve ser buscado na interdependência ou no fundo comum que une a todas elas. Neste caso, não seria melhor chamar tais pesquisas, não de transdisciplinares, mas de aquém-disciplinares? Não seria melhor dizer que elas buscam, não algo além delas, mas aquém ou anterior a elas? De todo modo, a divisão excessiva a que foram submetidas as ciências propõe um movimento de refluxo à sua própria lógica, por meio da busca de certas dimensões unificadoras.

Outro indício de que a discussão sobre o tema da unidade da ciência é atual diz respeito ao que é próprio à Universidade, à sua missão, na medida em que é o locus responsável por instituir 
o conhecimento como tal. Trata-se da dificuldade que temos de articular as dimensões da produção, reprodução e disseminação do conhecimento. Quais as razões pelas quais temos tanta dificuldade de articular ensino, pesquisa e extensão na Universidade? Uma das razões é a visão pautada pelo princípio da divisão e separação entre dimensões da ciência, desta vez não diretamente entre as ciências, mas no interior de cada uma delas. A lacuna, porém, parece ser a mesma: o princípio que separa as ciências divide também as dimensões do conhecimento em si, e ambos apontam para a falta de um princípio unificador.

O ensino também enfrenta esse problema. A separação entre as disciplinas trouxe a necessidade de unificá-las: elas não dialogam e permanecem fechadas em si mesmas. Mais uma vez, não se trata de construir a interdisciplinaridade, mas de resgatar a unidade perdida.

Um último indício da atualidade do tema da unidade das ciências pode ser visto por meio dos problemas atuais ligados à degradação do meio ambiente e aos problemas ecológicos em geral. Parece plenamente legítimo pensar que, se as ciências tivessem sido pensadas em sua unidade, os problemas ecológicos teriam sido percebidos muito mais facilmente e anteriormente ao tempo atual. Por que um engenheiro químico pensa em seu produto de forma isolada, sem se preocupar com as consequências? Se ele tivesse uma visão de conjunto, as perspectivas não poderiam ser diferentes? Os problemas ambientais e ecológicos exigem um novo redimensionamento das ciências e de suas divisões.

Esse quadro, rapidamente traçado aqui, parece indicar que houve diferentes tentativas de retorno ou de recuperação de alguma espécie de unidade do conhecimento cuja falta tem acarretado diferentes problemas. Há indícios de que o tema da unidade das ciências seja ainda um tema atual.

\section{Referências bibliográficas}

DESCARTES, René. Discurso do método; Meditações; Objeções 
Descartes: da unidade originária da razão e seus desdobramentos

e respostas; As paixões da alma; Cartas. 3. ed. São Paulo: Abril Cultural, 1983. (Os pensadores).

Meditações sobre filosofia primeira. Edição em latim e em português. Tradução de Fausto Castilho. Campinas, SP: Editora da Unicamp, 2004.

. Euvres de Descartes. Publiées par Charles Adam et Paul Tannery (AT). Paris: Vrin, 1996. 11 v.

. Regras para a direcção do espírito. Lisboa: Edições 70, 1985. 